\title{
FILOSOFÍA Y POESÍA EN SENTIDO POSTRAGICO: ORTEGA, HEIDEGGER Y ADORNO
}

\author{
Antonio Gutiérrez Pozo* \\ agpozo@us.es
}

RESUMEN Frente al positivismo racionalista, que sólo cree en el poder de la razón filosófica y que considera que el mundo es esencialmente racional y justo, y frente al tragicismo, que sostiene que la realidad carece de sentido y orden, y que por tanto sólo la poesía puede comprenderla, la actitud postrágica de Ortega, Heidegger y Adorno, afirma que sólo en la tensión entre filosofía y poesía puede salvarse el ser humano, porque sólo esa colaboración $y$ diálogo le permite acceder al ser.

Palabras claves filosofía, poesía, Ortega, Heidegger, Adorno

RESUMO Filosofia e poesia no sentido pós-trágico: Ortega, Heidegger e Adorno. Contra o positivismo racionalista, que só acredita no poder da razão filosófica e considera que o mundo é essencialmente racional e justo, $e$ em contraste com tragicism, que afirma que a realidade não tem significado e ordem, e, que portanto, somente a poesia pode compreendê-la, a atitude pós-trágica de Ortega, Heidegger e Adorno considera que apenas na tensão entre filosofia e poesia pode o ser humano salvar-se, porque somente essa colaboração dialógica entre filosofia e poesia lhe permite ter acesso ao ser.

Palavras-chave Filosofia, Poesia, Ortega, Heidegger, Adorno

* Profesor Titular da Universidad de Sevilla, Espanha. Artigo recebido em 21/2/2011 e aceito em 2/6/2011.

KRITERION, Belo Horizonte, $n^{\circ}$ 125, Jun./2012, p. 231-250. 
ABSTRACT Philosophy and Poetry from a Post-tragic Point of View: Ortega, Heidegger, Adorno. Against rationalist positivism, which only believes in the power of philosophical reason and considers that the world is essentially rational and fair, and in contrast with tragicism, which asserts that reality lacks meaning and order, and therefore only poetry can understand it, the post-tragic attitude of Ortega, Heidegger and Adorno states that only in the tension between philosophy and poetry the human being can be safe, because only that colaboration and dialog allows him to gain access to the being.

Keywords Philosophy, Poetry, Ortega, Heidegger, Adorno.

\section{Positivismo racionalista y tragicismo}

El momento histórico del origen de la filosofía suele comprenderse como un paso del mito al logos, es decir, como un tránsito del pensar no racional/ conceptual (mágico, mítico, poético o visionario) al pensar discursivo/ conceptual. Ahora bien, esta aparentemente sencilla descripción de un hecho histórico no es ingenua, ni inocente, ni es neutra. Ni tan siquiera es verdadera. Más bien, está cargada filosóficamente, de modo que no es una descripción sin más de un hecho histórico, sino una interpretación de ese acontecimiento determinada por una comprensión historicista/positivista de las relaciones entre los dos poderes configuradores del espíritu humano: lo mítico/poético y lo racional/conceptual, lo artístico/intuitivo y lo científico/discursivo, entre romanticismo e ilustración, entre poesía y filosofía. La relación entre poesía y filosofía es un trasunto de la vinculación más amplia entre mito y logos. Desde la perspectiva positivista, racionalista, ilustrada y progresista, la 'voluntad de razón' se apodera totalmente del espíritu humano, convirtiéndose el poder racionalizador o 'lógico' en su verdadera y única sustancia, y suprimiendo la potencia mítico/poética -y la 'voluntad de tragedia' que la acompaña-, o relegándola a una función accidental y secundaria en la economía espiritual humana. De acuerdo con la posición positivista, la ciencia, lo racional y lo conceptual, se quedan con el patrimonio del conocimiento, mientras que la poesía quedaría reducida a mera expresión de las emociones del sujeto. Desde esta perspectiva racionalista, el 'tránsito histórico' del mito al logos no es un simple paso sino un 'dejar atrás' una etapa pasada, una superación de algo inferior, para acceder a una etapa superior; se trata de entrar en una nueva 
época, filosófico/conceptual, dejando atrás y abandonando la anterior época del mito, la imaginación intuitiva y la poesía. De ahí se desprende que, para esta comprensión positivista, la actitud mítico-poética no es un poder permanente del espíritu humano sino algo del pasado, una etapa en el progreso del espíritu hacia su verdadera autorrealización mediante la racionalidad ilustrada.

La primacía de esta posición ilustrada/positivista en la comprensión moderna de la distribución de los poderes del espíritu resulta especialmente significativa en el ámbito de la reflexión estética, ámbito donde se miden las relaciones entre lo poético/estético y lo filosófico/conceptual. La constitución de la estética como disciplina filosófica en la obra de Baumgarten parte de la valoración del conocimiento estético -antes depreciado-, lo que lo hace ya digno de tratamiento filosófico. Semejante reconocimiento es el origen de la propia estética. A pesar de ello, la fundación baumgartiana de la estética está realizada desde la perspectiva positivista/racionalista. Aunque afirma que existen dos fuentes legítimas de conocimiento, Baumgarten subraya que una de ellas, la cognitio sensitiva, el modo de conocimiento propio de lo estético/ poético, es un conocimiento análogo a la cognitio rationalis, erigida en modelo de conocimiento, y que por tanto es "gnoseología inferior" frente a esta última, el modo de conocimiento propio de la filosofía ${ }^{1}$. Lo filosófico/conceptual entonces está por encima de lo estético/poético. El mismo esquema de fondo encontramos en el pensamiento de Hegel, que no sólo insiste en el modo baumgartiano de comprender las relaciones entre filosofía y poesía, sino que además lo amplía en sentido progresista/historicista, de modo que el arte acaba siendo superado por el concepto filosófico. Por eso, el arte para Hegel, como "manifestación sensible de la idea", es "algo del pasado (ein Vergangenes)" debido a que el arte ya "no es el modo supremo y absoluto mediante el cual el espíritu toma conciencia de sus verdaderos intereses", ni por tanto tampoco "para nosotros el modo supremo bajo el cual la verdad se hace existente", sino que el arte, "la forma sensible de la conciencia", es la forma de conciencia "más temprana para el hombre", "la primera e inmediata autosatisfacción del espíritu absoluto", de manera que finalmente "el pensamiento y la reflexión han superado el arte bello"2. El objetivo de este trabajo es mostrar que frente a esta comprensión positivista/racionalista de las relaciones entre filosofía y poesía, en la que impera la voluntad de razón, y a su contraria, la comprensión

1 Baumgarten, A. G., Aesthetica (facsímil de la ed. de Frankfurt, 1750), Hildesheim, G. Olms, 1986, § 1, 8, pp. 1, 3s.

2 Hegel, G. W. F., Vorlesungen über die Philosophie der Weltgeschichte (1822-1828), Band 1, Die Vernunft in der Geschichte, her. v. J. Hoffmeister, Hamburg, Felix Meiner Verlag, 1955, pp. 23ss, 141, 144, 151. 
trágica, expuesta esencialmente por Nietzsche y también por Unamuno, y que supone la valoración de lo mítico/poético sobre lo filosófico/conceptual, cabe una posición intermedia que pretende superar los extremos que representan esas dos actitudes, y situar las relaciones entre filosofía y poesía sobre un nuevo plano que, primero, evite la relación jerárquica que presuponen tanto el positivismo racionalista como el tragicismo, y, segundo, establezca una relación más conciliadora entre los dos poderes elementales espirituales del ser humano, la voluntad de razón y la voluntad de tragedia, sin suprimir la tensión entre ambos. Podemos denominar 'postrágica' a esta tercera posición que está representada por Ortega, Heidegger y Adorno.

A pesar de las diferencias conceptuales evidentes entre estos pensadores 'postrágicos' hay un nexo 'emocional' entre ellos que los vincula. La comprensión idealista de la filosofía nos ha acostumbrado a reconocer como filosófico sólo a las ideas, los mathemas, como si éstos existiesen solos y de forma independiente en un cielo de contenidos significativos. Contra este idealismo semántico, puede asegurarse que la filosofía no es sólo cosa de ideas o teorías. El pensar humano es al tiempo e indefectiblemente idea y emoción, significado y pasión, espíritu y ánimo. No hay auténtica filosofía que sea sólo idea. Toda filosofía contiene inseparablemente un eidos y un pathos. Además, la conexión entre mathemas y pathemas no es arbitraria sino esencial. Cada idea tiene necesariamente su pathos, su clima sentimental, y viceversa. Tan importante como estudiar las ideas de los pensadores y épocas, es comprender los estados de ánimo esenciales -o 'emociones filosóficas'- con los que están engarzadas y de los que brotan. Una afinidad de índole patética, que da lugar a una determinada intención filosófica, es lo que justifica la conexión entre Ortega, Heidegger y Adorno. Las enormes diferencias conceptuales que muestran sus respectivas filosofías no pueden ocultar la existencia de una semejanza radical en sus planteamientos de base, los cuales responden a su pathos epocal, diferente del pathos trágico de la época precedente que impregna las filosofías de Nietzsche y Unamuno. Ese pathos filosófico originario que fundamenta su conexión es precisamente aquella actitud postrágica, que concilia en términos de tensión lo filosófico y lo poético.

El origen de la filosofía presupone como condición de posibilidad de ella misma la ilusión de creer que se puede atrapar la totalidad de lo real mediante la luz natural del pensamiento. Este optimismo racionalista es lo que llamamos 'voluntad de razón'. Lo que añadió el positivismo racionalista e ilustrado a la voluntad de razón fue el imperialismo excluyente de la razón conceptual y discursiva, la disolución del espíritu trágico, y el consecuente destierro de la poesía - más aún, de la potencia artística en general. La ilustración racional, 
segura del poder universal de configuración de la razón para disipar toda ininteligibilidad, lo empleó para disolver y desterrar para siempre el mito y la poesía como poderes elementales del espíritu y alternativos. Esa ilusión epistemológica se completa con otra de orden metafísico/moral: poder hacer inteligible la realidad supone también justificarla. Creer que se puede aclarar racionalmente la realidad en su totalidad disipando todo residuo de oscuridad, implica presuponer metafísico/moralmente que el mundo es en esencia racional, bueno, justo, ordenado y bello. La voluntad de razón sintetiza esos dos optimismos radicales -epistemológico y metafísico/moral. Sócrates representa al héroe de esta voluntad de razón, al héroe filosófico por excelencia, y Hegel, tras afirmar la identidad de lo racional y lo real (Was vernünftig ist, das ist wirklich; und was wirklich ist, das ist vernünftig), $\mathrm{y}$ deducir de ahí la justicia metafísica del mundo ("el mundo real es tal y como debe ser (die wirkliche Welt ist, wie sie sein soll)"), representa la culminación racionalista de la voluntad de razón ${ }^{3}$.

Ahora bien, la crisis de la razón racionalista y positivista que cultivó la ilustración estaba ya escrita en su propia constitución racionalista. La razón ilustrada dejó sin atención la existencia, debido a que no pudo conocer su hondura, sentido y complejidad. Era una razón facultada tan sólo para satisfacer las exigencias de la lógica, pero incapaz de satisfacer al hombre real y viviente. La existencia humana está atravesada por una exigencia de sentido radical que la constituye esencialmente. Por eso no puede haber auténtico existir humano sin algún tipo de conciencia que se mida con esa exigencia surgente que forma parte de la vida. La razón ilustrada no pudo satisfacer esa exigencia de sentido, y esa imposibilidad, al tiempo que provocó una ruptura entre la razón y la vida, acabó por disolverla. La misma esperanza constitutiva del proyecto ilustrado, consistente en creer que el pensamiento racional podría volver trasparente la totalidad de la realidad, empujó a la razón -con Kant y Schopenhauer- hasta el límite de sus fuerzas y allí experimentó el abismo de la existencia, la nada, el misterio y la irrebasable oscuridad que trascienden las capacidades de la racionalidad. La razón sucumbe cuando, en su afán por aclarar todo lo real conceptualmente, llega a su límite y conoce lo ilógico, lo ininteligible. Entonces se aniquila a sí misma volviéndose escéptica porque experimenta aquello que la niega, aquello que pone en cuestión el principio de inteligibilidad, la base sobre la que se apoya su propia existencia. Al sufrir la quiebra de este principio, la razón padece su propia negación y cuestiona 
su propio derecho a existir. La confianza excesiva en el poder disolvente y desencantador de la razón acabó finalmente con la propia voluntad de razón y la fe en su capacidad clarificadora. Unamuno escribe que "la disolución racional termina en disolver la razón misma, en el más absoluto escepticismo"4.

La crisis de la razón revela que no hay sentido, sino experiencia del abismo, el vacío, la nada y el absurdo. De acuerdo con el paralelismo entre lo epistemológico y lo metafísico/moral, hay que afirmar que si la razón no puede aclarar la realidad se debe a que la propia realidad carece de sentido y razón, ni es justa ni bella, sino que es abismática, oscura y azarosa. La crisis de la razón revela la negrura del ser. Este es el pesimismo trágico. Nietzsche, justamente tras las experiencias intelectuales de Kant y Schopenhauer, denomina "conocimiento trágico" tanto al conocimiento que alcanza la razón de su propio límite y de la impenetrable oscuridad que la amenaza con la destrucción, como al conocimiento de que el mundo no es bueno, justo y bello, sino sinsentido, caótico, horrible y doliente ${ }^{5}$. Tras el imperialismo de la razón, la crisis de la razón; tras su alucinación, la desilusión. Del mundo racionalizado y justo de Hegel al mundo trágico de Nietzsche. El tiempo histórico de la 'crisis fin de siglo' es un magnífico ejemplo de esta alternancia sustancial de los dos poderes espirituales, ilustración y romanticismo. La voluntad de razón misma llevada hasta el extremo desemboca en voluntad de tragedia. La voluntad de la razón de volver inteligible radicalmente lo real la encamina a experimentar su eterno límite y la conduce a la tragedia de sí misma. Por ser este conocimiento trágico conocimiento de la oscuridad de la realidad última, también lo es del abismo insalvable que separa a la razón del ser y de la existencia considerados en su radicalidad. El modelo positivista de racionalidad ha provocado un abismo entre el ser y la lógica, entre el mundo de la vida y el corazón por un lado, y el mundo de la cultura y la razón por otro, que quedan enfrentados entre sí. Frente al absolutismo panracionalista de Hegel que establece a priori la identidad entre realidad y razón, Unamuno propuso esta fórmula que bien podría valer como lema final del tragicismo: "Todo lo vital es irracional, y todo lo racional es antivital"6. El racionalismo afirma la razón, pero no puede atender la vida y su exigencia de sentido. El tragicismo cultiva la vida, pero la deja sin razón, sin sentido ni verdad.

4 Unamuno, M., Del sentimiento trágico de la vida (1912), Madrid, Espasa-Calpe, 1980, p. 105.

5 Nietzsche, F., Die Geburt der Tragödie (1872), Sämtliche Werke: Kritische Studienausgabe in 15 Bänden, her. v. G. Colli und M. Montinari, München, Deutscher Taschenbuch Verlag/De Gruyter, 1980, Bd. 1 § 15, p. 101. 6 Unamuno, op. cit., p. 95. 
La contradicción entre la razón y la existencia, que no cesa de clamar por un sentido que no puede encontrar en la cultura progresista de la razón positivista, fue la causa del fracaso existencial de la razón ilustrada. El extremo racionalista culminó desembocando en su extremo opuesto tragicista. La ilustración pasó de la voluntad de razón a la voluntad de tragedia, o sea, a la tragedia de la razón, lo que supuso la entrega sin reservas al arte, la poesía y el mito, concebidos entonces como respuestas trasracionales de los problemas que aquella razón plantea y que ella misma no puede resolver. Dado que el sentido que proporciona la cultura científica no responde a las expectativas de la vida, hubo que localizar el sentido en otra esfera, en el ámbito mitopoético. La crisis de la razón provocó la entronización de lo poético, de la voluntad de creación de sentido. El conocimiento trágico que logra la razón al asomarse a su límite no puede ser soportado, según Nietzsche, sin el arte, configurado ya como protección. Por esto, el espíritu trágico es la experiencia de la antítesis entre razón y poesía, sobre la base de la conciencia de que no hay sentido sino abismo. La tragedia es la vivencia de la escisión entre razón/ vida, sentido/existencia y filosofía/poesía. El alma trágica representa, pues, la antinomia entre la experiencia del vacío, del sinsentido del mundo, y la exigencia de afrontarlo desde el espíritu poético. Sólo en el arte encuentra la razón un remedio suficiente para afrontar el miedo que experimenta ante sus propias y trágicas consecuencias ${ }^{7}$. El desenlace último de la época ilustrada ha sido por tanto paradójicamente la época trágica de Nietzsche y Unamuno. El pathos ilustrado concluyó en el pathos trágico. Esta es la dialéctica de la razón ilustrada. Del mito al logos, para luego volver al mito. Este movimiento dialéctico no representa sólo un acontecimiento histórico, sino también -y sobre todo- la dialéctica misma de las fuerzas configuradoras del espíritu humano, que va tomando forma concreta en distintos momentos históricos.

El compromiso del tragicismo de Nietzsche con el arte, a diferencia de la actitud adoptada por el joven Hegel, Hölderlin o Schelling, no tiene el objetivo de salvar la verdad metafísica, sino que representa más bien su superación. Arte y verdad, poesía y filosofía, lejos de coexistir en armonía, están enfrentados por el espíritu trágico. Justo en este punto se produce la separación entre el tragicismo de Unamuno y de Nietzsche. El unamuniano permanece en la lucha-duda agónica- entre la razón y la vida, mientras que el nietzscheano disuelve la razón para entregarse a una vida que ama la ilusión y el engaño ${ }^{8}$. El arte para Nietzsche es ficción, ilusión, no órgano de la verdad, y 
entendido como tal: "El arte vale más que la verdad" y, dado que "la verdad es fea (häßlich)", horrible, trágica, "tenemos el arte para no perecer a causa de la verdad" 9 . La verdad es fea porque es pesimista, porque enseña que en el mundo no hay orden ni sentido ni justicia, sino dolor, crueldad y azar. El espíritu trágico sólo puede soportar esta experiencia pesimista mediante el consuelo de la ilusión, con la ficción de sentido que representa el espíritu creativo del arte. El arte es para Nietzsche la "actividad metafísica" propia del hombre precisamente porque salva de la verdad, y a esta operación de salvación de la fealdad del mundo mediante el arte la llama "justificación estética de la existencia (ästhetische Rechtfertigung des Daseins)" ${ }^{10}$. El arte que abraza la tragedia es enemigo de la verdad, es ficción e irrealidad, "santificación de la

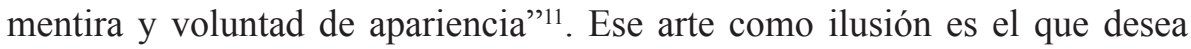
la vida para protegerse y soportar la trágica verdad: "La vida quiere ficción (Täuschung), subraya Nietzsche, vive de la ficción" 12 . Una vida que ama la ilusión, tenía que acabar convirtiendo al arte -previamente entendido como región de apariencias y ficciones- en potencia sustancial.

Pero Nietzsche va más allá. Pretende explicar desde el conocimiento trágico la voluntad de razón y la filosofía. La comprensión positivista que enfrentaba la filosofía al arte y la poesía es ingenua. Para Nietzsche, Sócrates, máximo exponente de la fe en la filosofía, es un trágico, acaso el más trágico; tanto experimentó Sócrates la esencia trágica de un mundo sin sentido ni razón, un abismo sin justicia ni orden, sometido al dolor y a la serpiente del caos, que inventó -por miedo (Furcht) ante el pesimismo trágico y como escapatoria (Ausflucht) de él, como una "defensa sutil contra la verdad"- la ilusión de la claridad filosófica y la justicia ${ }^{13}$. El 'mundo verdadero' socráticoplatónico, el mundo racional y justo, objeto de la filosofía, es una mentira inventada para poder soportar la verdad trágica del mundo sin razón, mediante la creación de una 'verdad fuerte' (e ilusoria) que niega la horrible verdad del abismo. La voluntad de razón surgió entonces como miedo ante la tragedia y el pesimismo. "Oh Sócrates, Sócrates, concluye Nietzsche, ¿fue ése acaso tu secreto (Geheimnis)? Oh ironista misterioso (geheimnisvoller Ironiker), ¿fue ésa acaso tu ironía (Ironie)?"14. Sócrates y Nietzsche han

9 Nietzsche, Nachgelassene Fragmente (1887-1889), KSA, Bd. 13, p. 227 (fr. 14 [21]), p. 500 (fr. 16 [40]), p. 522 (fr. 17 [3]).

10 Ibid., p. 227 (fr. 14 [21]); Nachgelassene Fragmente (1882-1884), KSA, Bd. 10, p. 238 (fr. 7 [7]).

11 Nietzsche, Zur Genealogie der Moral. Eine Streitschrift (1887), KSA, Bd. 5, III, § 25, p. 402.

12 Nietzsche, Menschliches, Allzumenschliches (1878), Erster Band, Vorrede 1, KSA, Bd. 2, p. 14.

13 Nietzsche, Versuch einer Selbstkritik, Die Geburt der Tragödie (1886), § 1, p. 13.

14 ld. 
experimentado el mismo conocimiento trágico, pero Sócrates reacciona con miedo ante el pesimismo, mientras que Nietzsche dice sí a la vida tal como es, afirma la tragedia y también el arte (ficción) como fuerza antimetafísica capaz de soportar la verdad mediante el espíritu creativo. La desavenencia entre la filosofía y la poesía entendida como relación entre verdad e ilusión, llevó a Platón a condenar a la poesía (y al arte en general). El positivismo racionalista siguió esta dirección. El romanticismo del idealismo alemán, en cambio, comprendió el arte y la poesía como verdaderos órganos de la verdad, por encima de la razón. En Nietzsche, la voluntad de poder creativa del arte vale más que la verdad metafísica o filosófica, porque sólo esa fuerza nos permite vivir en un mundo trágico. Pero en todos estos casos filosofía y poesía se hallan una respecto de la otra en relación jerárquica o de exclusión, de modo que una supera a otra, o la niega, o vale más, o la condena. La actitud postrágica ha pretendido superar este planteamiento para llegar a ponerlas en relación de armoniosa tensión.

\section{El postragicismo}

La conclusión del pathos trágico es notoria: el abismo entre la cultura y la vida no podía terminar sino en el enfrentamiento entre la filosofía y la poesía. Lo que caracteriza a la generación postrágica de Ortega, Heidegger y Adorno, es el proyecto de superación de esa doble contradicción. El resultado que arroja el análisis de la realidad emprendido por estos pensadores tiene elementos básicos comunes, que continúan, desarrollan y amplían la comprensión ya efectuada por la generación trágica. También ellos - desde el mundo racionalizado y tecnificado en que estamos- parten de la crisis de la razón, de la negatividad del mundo y de la situación alienada del hombre. Por eso pueden rastrearse restos del espíritu trágico de la generación anterior en su pensamiento. La filosofía del joven Ortega (hasta 1910) deja traslucir cierta concepción trágica del arte como respuesta y complemento de una ciencia incapaz de lograr el conocimiento último de lo real: "Esta es la tragedia original de la ciencia: trabajar para un resultado que nunca logrará plenamente. De la tragedia de la ciencia nace el arte. Cuando los métodos científicos nos abandonan, comienzan los métodos artísticos" ${ }^{\prime 15}$. Si nos dejamos llevar por una lectura demasiado precipitada no resulta extraño descubrir en la filosofía Heidegger la conversión del pensamiento en poesía o mística. Y Adorno puede 
parecer el más trágico si sólo insistimos en su filosofía de la desesperación y en la negra y tenebrosa oscuridad que, a su juicio, define a la realidad ${ }^{16}$. Pero será el desenlace final lo que marque la diferencia categorial de la generación postrágica respecto de su antecesora, en tanto que representa una forma distinta de entender las relaciones entre filosofía y poesía.

La comprensión negativa del mundo que constituye el punto de partida de la reflexión postrágica consiste en el desarrollo del concepto de desencantamiento (Entzauberung) del mundo que expuso Weber: la tecnificación del mundo lo ha convertido en objeto disponible para un sujeto, en 'recurso', reduciéndolo todo a cantidad y cálculo, de manera que las cosas pierden 'su' sentido, 'su' valor, 'su' diferencia, y todo se hace lo mismo, se homogeneiza, todo se iguala ${ }^{17}$. Hoy estamos en un mundo donde no hay ya cosas, menos aún seres, sino sólo recursos, o sea, realidades medibles, objetivables y dominables por un 'sujeto', que es en lo que, a su vez, ha devenido el ser humano en un mundo de objetos y recursos. Todo es recurso; la naturaleza y la cultura se comprenden y existen sólo como 'recursos naturales' y 'recursos culturales' que están 'a la mano' del sujeto. Extirpado todo sentido y valor del mundo, todo se ha desvirtuado y perdido su verdad. Parafraseando a Heidegger, la naturaleza se ha convertido en objeto, en materia prima; la cultura se reduce a su explotación como negocio, la política deviene simple técnica administrativa y los ideales son prefabricados por una industria cultural ${ }^{18}$. El ideal del hombre actual es poder disponer de una buena administración, razonable y coherente. Un mundo objetivado y ordenado colma nuestras aspiraciones más humanas. Contra esta disolución científico/técnica del mundo -del ser- en una red sistemática de hechos, Ortega aplaudió la "gigantesca innovación" que supuso la fenomenología de Husserl al afirmar la recuperación de un mundo con sentido, que rezuma logos y ser por todos sus poros ${ }^{19}$. Esta restauración del logos sólo podía localizarse en un ámbito mundano preconceptual, una esfera originaria que se le escapa a la ciencia: el mundo vital, la región de las experiencias antepredicativas o del saber vital prerreflexivo.

16 Adorno, T. W., Ästhetische Theorie (1969), Gesammelte Schriften, Frankfurt am Main, Suhrkamp, 1984, p.65.

17 Heidegger afirma que en esta época de la razón que calcula "lo cuantitativo se transformó en una peculiar cualidad" (Einführung in die Metaphysik (1935), Gesamtausgabe, Bd. 40, Frankfurt am Main, Klostermann, 1983, p. 49).

18 En esta descripción de lo esencial del mundo contemporáneo hemos seguido principalmente a Heidegger: "vergegenständlichte Natur, betriebene Kultur, gemachte Politik, übergebauten Ideale" (Überwindung der Metaphysik (1936-1946), Vorträge und Aufsätze, GA, Bd. 7, 2000, p. 78), pero el diagnóstico es perfectamente compatible con los análisis de Ortega (La rebelión de las masas) y Adorno (Dialektik der Aufklärung).

19 Ortega y Gasset, Max Scheler (1928), OC, t. IV, pp. 509s. 
Según Heidegger, la situación del hombre en el mundo tecnificado se encuentra esencialmente expuesta en estos versos del poema Mnemosyne de Hölderlin: "Un signo somos, carente de sentido (deutunglos); / sin dolor estamos, y en tierra extraña / casi hemos perdido la palabra" ${ }^{20}$. En esta época técnica y sombría, de dioses huidos (entflohenen Götter), destrucción (Zerstörung) de la tierra y masificación (Vermassung) del hombre, el "oscurecimiento (Verdüsterung) del mundo" no alcanza la "luz del ser (Licht des Seyns)" "21. El ser humano está perdido, en un lugar inhóspito donde no puede reconocerse en lo propiamente suyo. En 'tierra extraña' es sin sentido. No 'es' (no 'está en') lo propiamente suyo: 'lugar del ser', verdad. Está (es) fuera de la luz del ser, fuera de la verdad, (casi) sin palabra para 'decir el ser', actividad que constituye el ser del hombre. El mundo está oscurecido, no llega al ser. El ser humano está (es) fuera de sí, alienado ${ }^{22}$. Sin dioses, sin ser, a la espera del 'dios que viene', o sea, de una nueva revelación epocal, estamos en la época del nihilismo, en un tiempo menesteroso (dürftige Zeit); tan menesteroso, destaca Heidegger, que ni siquiera experimentamos la falta de $\operatorname{dios}^{23}$. Hemos olvidado incluso el olvido del ser. También Ortega sostiene que a esta situación angustiosa y alienada, "se ha añadido para aumentar el sufrimiento de los europeos, la falta absoluta de claridad sobre eso que sufrían": "El dolor quedó y queda multiplicado por la tiniebla en que se producía" 24 . Esto es lo peor que podía pasarle al hombre: no saber siquiera lo que le pasa, ni saber quién es. Lo que nos pasa, por mor de la falta de claridad sobre lo que nos pasa, está ocurriendo 'sin dolor', es decir, está ocurriendo, pero nosotros no lo experimentamos como tal, y por eso el hombre de la voluntad de poder, tecnificado y alienado, cree que está arraigado, que está en su ser, y cree también que sabe de sobra quién es. No siente el dolor del desarraigo, la extranjería y la oscuridad. Pero esa conciencia sentiente sería a fin de cuentas lo único que podría ponerle en camino de salvación: "La conciencia del naufragio, al ser la verdad de la vida, es ya la salvación" 25 . Sin conciencia del dolor y la alienación no hay salvación. El peor peligro, insiste

20 Apud Heidegger, Was heißt Denken? (1952), Vorträge und Aufsätze, p. 135.

21 Heidegger, Aus der Erfahrung des Denkens (1947), Aus der Erfahrung des Denkens, GA, Bd. 13, 1983, p. 76; Einführung in die Metaphysik, p. 48.

22 No es casualidad por tanto que Heidegger haya llamado la atención sobre este concepto marxista (cf. Brief über den Humanismus (1946), Wegmarken, GA, Bd. 9, 1976, pp. 339s).

23 Heidegger, Einführung in die Metaphysik, p. 48; Heidegger, Hölderlin und das Wesen der Dichtung (1936), Erläuterungen zu Hölderlins Dichtung, GA, Bd. 4, 1981, p. 47; Heidegger, Wozu Dichter? (1946), Holzwege, GA, Bd. 5, 1977, p. 269; Nietzsches Wort 'Got ist tot' (1943), Holzwege, p. 264.

24 Ortega y Gasset, Meditación de Europa (1949), OC, t. IX, p. 248; Conferencias sobre Goethe (1949), OC, t. IX, p. 555.

25 Ortega y Gasset, Pidiendo un Goethe desde dentro (1932), OC, t. IV, pp. 397s. 
Adorno, es que pensemos que no hay peligro, que todo va bien ${ }^{26}$. Pero no todo está perdido: como escribió Hölderlin en Mnemosyne 'casi' hemos perdido la palabra. Contra la indiferencia del 'sin dolor' que eternizaría la condición alienada del hombre en un mundo de apariencia humana, todavía queda una esperanza para que el ser humano exprese la verdad y le dé voz al dolor, una esperanza en suma para que se abra en el hombre la pregunta por el ser; para que el hombre sea en definitiva 'lugar del ser', verdad. Ahora bien, Adorno considera que el último refugio de la esperanza en un tiempo humanizado y pacificado, liberado de la lógica del dominio, es la propia desesperación ante la condición alienada del hombre en el mundo de la voluntad de poder, la conciencia desesperada de la prohibición de la esperanza ${ }^{27}$.

La experiencia de lo terrible de lo real no termina en el pensamiento de Ortega, Heidegger y Adorno transformándose en disolución de la razón, oposición trágica entre pensamiento y vida, y vacío de sentido de la vida. Lo que se proponen es, más bien, suturar la herida abierta entre razón y existencia para que la vida pueda lograr sentido. Tal es el núcleo de significado de la perspectiva postrágica que representan. El proyecto de conciliación entre razón y existencia, entre cultura y vida, subyace a las posiciones filosóficas de Ortega, Heidegger y Adorno, y ello no por casualidad. Tras el enfrentamiento a que fueron sometidos lo racional y lo vital por la tradición, tanto intelectualista como tragicista, el programa de interpenetración planteado por la actitud postrágica es, según Gadamer, un "signo de nuestro tiempo", la misión que nos pone a la "altura de los tiempos' ${ }^{28}$. La tradición racionalista y tragicista, al enfrentarlos, ha propuesto a la generación siguiente en forma de imperativo la tarea de conciliación entre razón y existencia. Además, el binomio que forman el mundo tecnificado y la alienación de la existencia no es sólo la última consecuencia de la antítesis entre razón y existencia, sino su forma suprema, de modo que responder a esta antítesis significaría satisfacer adecuadamente aquel binomio que condensa el conflicto del mundo actual. Resulta evidente que esa operación conciliadora no puede acometerla la misma razón conceptualista y positivista. Nos volvería a abocar al abismo trágico. Pero tampoco puede suponer una abdicación sin más del pensamiento racional. Hace falta una razón que no se enfrente a la vida. La razón necesita el concurso del arte. Pero es que además, y habida cuenta del paralelismo

27 Adorno, Philosophische Terminologie (1962-1963), t. II, Frankfurt a. M., Suhrkamp, 1997, p. 182.

28 Gadamer, G. H., "W. Dilthey y Ortega y Gasset: un capítulo de la historia intelectual de Europa", Revista de Occidente, $48-49$ (1985), p. 88. 
que descubrimos en la generación trágica entre las oposiciones razón/vida y verdad/arte, una relación más saludable y menos excluyente entre razón y existencia producirá también una conexión más cordial entre la filosofía y la poesía. De esta manera se superan en un solo movimiento aquellas dos funestas oposiciones que determinaron el pathos trágico. Así que la nueva perspectiva que trae nuestro tiempo, y que está representada en el pensamiento de Ortega, Heidegger y Adorno, supone una superación de la antítesis trágica de raíz positivista entre razón y vida, filosofía y poesía.

El enfrentamiento excluyente entre razón/vida y filosofía/poesía es el primer paso para luego o bien entender el arte como lugar de irracionalidad, y la ciencia como poseedora exclusiva de los derechos del conocimiento; o bien, previa desvaloración de la razón, para convertir el arte -y especialmente la poesía- en modelo de la filosofía. La generación postrágica pretende evitar el antagonismo razón/existencia, filosofía/poesía, logos/mito, pero tampoco se propone deshacerlo a favor de alguno de los dos miembros. Se opone tanto a la oposición excluyente, como a la indistinción y la fusión de ambos por absorción o supeditación de uno a otro. Ortega y Adorno son bastante claros al respecto y su pretensión de convergencia es patente. Heidegger parece más cerca de deshacer aquel antagonismo en beneficio de la poesía y en detrimento de la razón. Pero no nos engañemos con Heidegger. Es cierto que Heidegger ha expuesto su pensamiento 'sobre' el ser desde la poesía -y sobre todo desde Hölderlin-, pero esto no implica que hubiese abandonado el camino de los conceptos a favor de la poesía. Heidegger desde luego se opone a la disolución conceptual del arte y la poesía en la filosofía, pero también se opone al pensamiento que abdica de la racionalidad para convertirse en poesía o en mística. Así es como lo interpreta Adorno ${ }^{29}$, pero realmente el proyecto heideggeriano no consiste en otra cosa que en ponerse al margen de la tradición metafísica, supuesta en aquella contraposición, para así poder ponerse en camino de otro más pensar más originario e integrador, que escape de aquella discrepancia antagónica y trágica, y no invalide el logos filosófico.

Lo que Heidegger pretende más bien es que la razón de la filosofía, para recuperarse de su 'enfermedad', de su conversión en una lógica nihilista de dominio, se vuelva sobre lo que ha olvidado: la poesía y el mito. Fue aquel olvido lo que la llevó al enfrentamiento con la poesía. En primer lugar, esta vuelta para Heidegger supone que la poesía y la razón están 'en lo mismo' (im selben) pero diferentes en su esencia; separados por un abismo (Kluft), 
“están uno frente al otro (zueinander)", y -según el verso del Patmos de Hölderlin- "habitan sobre las montañas más separadas"30. Pero, en segundo lugar, esta separación no implica enfrentamiento ni oposición sino vecindad (Nachbarschaft). Filosofía y poesía son diferentes, están separadas, pero viven cerca (nahe). Por tanto, Heidegger ni asume la quiebra de la racionalidad, ni abraza el poeticismo o el misticismo. La razón calculadora que ha olvidado la poesía y el mito para desembocar en el imperio cuantitativo de la tecnificación, la razón conceptualista y metódica que no cuenta con ellas y actúa por sí sola, sin apoyarse en su matriz mitopoética, ese es el modelo de racionalidad que Heidegger condena. La intención filosófica central de Heidegger es devolver la razón a su enraizamiento original en la matriz mitopoética. Además, sólo la colaboración de filosofía y poesía puede devolver al hombre a su propio ser -el 'habitar poético' del mundo-, hasta ahora alienado por el sujeto de la voluntad de poder, irrespetuoso con el mundo ${ }^{31}$. El hombre sólo cuidará el mundo y a sí mismo cuando lo conceptual y lo poético converjan. En este sentido sostiene Heidegger que "Nur noch ein Gott kann uns retten (sólo un dios puede todavía salvarnos)" 32 . En un mundo totalmente racionalizado, de 'dioses' huidos, tecnificado y sometido al método científico/matemático, sólo nos puede salvar un 'dios', es decir, una revelación que abra un clima espiritual que logre descentrar la razón para que entre en contacto con el logos mitopoético, y que así nos permita abandonar el logocentrismo en que estamos inmersos.

La posición final que representa la actitud postrágica supone afirmar la separación y diferencia entre razón y vida, filosofía y poesía, concepto y arte, $\mathrm{y}$, al tiempo, la integración de esos elementos, evitando tanto la disolución de uno en otro que los identifique mediante la subordinación de un elemento al otro, como el puro antagonismo estéril, y la relación jerárquica y excluyente. Se trata de una convergencia entre filosofía y poesía que los mantenga uno con otro, en tensión fecunda de colaboración, de complementariedad, de modo que se necesiten mutuamente y se remitan uno al otro. La actitud postrágica pretende por tanto que el enfrentamiento entre filosofía y poesía no se establezca en términos (negativos) de alternativa y elección, como si se tratase de una contradicción entre ambas, sino de forma positiva como tensión fértil,

30 Heidegger, Was heißt Denken?, p. 137; ... Dichterisch wohnet der Mensch ... (1951), Vorträge und Aufsätze, p. 196; Nachwort zu 'Was ist Metaphysik' (1943), Wegmarken, p. 312.

31 Cf. Gadamer, Los caminos de Heidegger (tr. de A. Ackermann), Barcelona, Herder, 2002, p. 371; Cerezo, P., "El claro del mundo: del logos al mito", Nuevo romanticismo: la actualidad del mito, Cuadernos del Seminario Público de la Fundación Juan March, Madrid, no 1, 1997, p. 71.

32 Heidegger, Spiegel-Gespräch mit M. Heidegger (1966), Reden und andere Zeugnisse eines Lebensweges, GA, Bd. 16, 2000, p. 672. 
de manera que dicha tensión mutua constituya la esencia tanto de la filosofía como de la poesía. Tras el positivismo racionalista y el tragicismo, lo que el postragicismo considera saludable para la cultura y la existencia humanas es la afirmación del propio conflicto insuperable entre filosofía y poesía, o sea, permanecer en la lucha constante y sin vencedor entre el espíritu filosófico y el espíritu trágico. La filosofía reconoce en la tragedia su límite, la advertencia de que su aspiración de sentido se hundirá en la nada, la imposibilidad de que la voluntad de razón ilumine todo lo real de forma absoluta. La tragedia, a su vez, reconoce en la filosofía una esperanza (ilusa e irrealizable tal vez, pero irreducible y eterna) en que la voluntad de razón pueda disolver toda oscuridad y clarificar el sentido de la realidad. La tragedia impugna el optimismo de la razón filosófica, que confía en aclarar la existencia y encontrar sentido, y acaba burlándose de su ilusa voluntad de razón, y considerándola producto de la ingenuidad que no ve el vacío, el abismo. Por su parte, la filosofía censura de modo permanente a la tragedia su pesimismo radical, considerándolo hijo de la ceguera que no quiere ver los logros de la racionalidad. Esta es la herencia que nos ha legado la generación postrágica: tragedia y filosofía, poesía y razón, en eterna tensión de retroalimentación. Tragedia y filosofía se necesitan mutuamente: la razón ha de enfrentarse al espíritu trágico si quiere justificarse a sí misma, y no hay verdadera tragedia si no pasa por la experiencia del fracaso de la razón, desenmascarando sus pretensiones. Sólo así podemos aprender que no hay poesía sin la experiencia del misterio, sin experimentar la quiebra de la arrogante voluntad ilustrada de razón que aspira a clarificarlo todo.

La perspectiva postrágica comprende pues la relación entre filosofía y poesía como un diálogo sostenido sobre la diferencia entre ambas. El diálogo verdaderamente no es sino un movimiento constante entre los interlocutores, los cuales, en dicho trasiego, están en permanente y recíproca retroalimentación. No están por tanto en un diálogo de mediación, porque no anula las diferencias, sino de complementariedad. Cada uno se ve remitido al otro porque en él encuentra lo que no tiene. Heidegger afirma explícitamente que filosofía y poesía se "copertenecen (zusammengehören)", y exige un diálogo (Zwiesprache) que acerque aquellas montañas tan separadas ${ }^{33}$. Efectivamente, Heidegger, al pedirle al logos que no olvide 'colocarse' sobre su matriz mitopoética, parece más cerca de aquella postura poeticista que Ortega o Adorno, pero no la abraza en absoluto. Heidegger abandona pensamiento en la experiencia de la palabra según M. Heidegger”, pp. 317ss. 
ciertamente la comprensión de la relación entre filosofía y poesía basada en el antagonismo, pero no -como sostiene Adorno- para invalidar el logos, sino para que se vuelva hacia lo que él mismo ha olvidado y donde está su fuente y guía. Lo que Heidegger reclama es que el logos no olvide la (su) dimensión mitopoética, no que se disuelva en ella abdicando de sí mismo. Se trata de que recupere su raíz vivificante en la poesía, se trata en suma de reintegrar el espíritu mitopoético en el logos. Ortega y Adorno conciben lo artístico y lo filosófico, lo intuitivo, mimético y expresivo, por un lado, y lo conceptual y discursivo por otro, como dos troncos separados de la conciencia, pero piden su convergencia, la incorporación mutua de uno en otro. La gran diferencia entre estos tres pensadores reside en que Heidegger pretende hablar del arte, la naturaleza, el ser o la técnica, sin convertirlos en objetos nuestros, mientras que el discurso de Ortega y Adorno es totalmente 'humanista/metafísico'. Pero los tres coinciden en el planteamiento esencial de que al pathos trágico le suceda la exigencia de colaboración entre racionalidad y arte: al enfrentamiento no le sigue la fusión ni la síntesis sino el diálogo entre concepto y fantasía, logos y mito, filosofía y poesía. Ni el mito precede al logos, que luego le superaría definitivamente, como si el mito fuese una etapa 'pre-lógica', ya pasada y superada; ni el mito es la sustancia nutriente última, de manera que al logos sólo le quedaría la posibilidad de volverse hermenéuticamente sobre él, convertido ya en única fuente de sentido y verdad. Esta nueva posición filosófico-estética de carácter postrágico se revuelve en suma tanto contra aquella estética que, desde Baumgarten hasta Hegel, subordina la cognitio sensitiva a la cognitio rationalis, a pesar de reconocer su relevancia cognoscitiva; como contra aquella estética romántica que parte de la afirmación del conocimiento intuitivo del arte como verdadero tronco inicial y originario del conocer, de manera que el concepto sólo sería un movimiento secundario -en sentido temporal y esencial- volcado sobre aquel primer y radical conocimiento.

Más con Hegel que con Kant, Ortega, Heidegger y Adorno conectan el arte con el conocimiento y la verdad, pero no según el modelo del idealismo alemán para restaurar la metafísica violenta de la identidad. Los horrores de la época y las críticas de Kierkegaard y Nietzsche a la metafísica significaron para ellos el derrumbe del idealismo alemán. Se vuelve entonces a una conexión entre arte y verdad sin tener que pagar el tributo de la recuperación de la metafísica. La superación de la contraposición entre razón y existencia es lo que les permite abandonar el principio de identidad para que el pensar racional se vuelva cordialmente sobre la vida. A ese programa de cordialidad obedece el hecho de que los tres cifren la salvación del hombre y del mundo en la superación del idealismo del concepto que se identifica a priori con el 
ser, y cuya traducción material es la tecnificación irrespetuosa del mundo y el humanismo de la voluntad de poder. La salvación por tanto depende de la liberación del imperio irrespetuoso del mundo humano. Sólo hay hombre por todas partes y se trata de abrirse a lo que es, a lo otro respecto del hombre: a las cosas pequeñas de la experiencia antepredicativa de la vida (Ortega), al ser para que escuchemos la palabra que nos interpela desde él (Heidegger), y a la realidad individual y concreta que sufre en silencio y que pide que le den voz (Adorno). El hombre sólo se salva en diálogo -tensión fecunda- con lo que no es él -la circunstancia, el ser, lo individual/concreto. La salvación sólo podrá provenir del acceso al ser, o sea, de la salida de los límites del mundo (humanizado) cuyos patrones ya están establecidos e impuestos a priori por la voluntad de poder humana. Ortega, Heidegger y Adorno son efectivamente críticos del mundo y de la cultura actuales, sometidos a las categorías de tecnificación, dominio y alienación, pero al tiempo son pensadores de lo que es. Heidegger p. e. no es un mero crítico de la técnica en clave romántica, sino ante todo un pensador del ser de la técnica. En la época turbulenta y trágica que les tocó vivir (guerras mundiales y civiles, campos de concentración y exterminio, bomba atómica), el horror que experimentaron no sólo no impidió sino que impulsó su muy fenomenológica voluntad de ver y mostrar. Puede decirse en términos muy amplios que la fórmula heideggeriana: Einblick in das was ist, una mirada a lo que $\mathrm{es}^{34}$, representa el camino de salvación válido para todos. El héroe del nuevo pensamiento es el náufrago que sale de los patrones ya dados que configuran el mundo y se ahoga en la experiencia de la realidad vital (Ortega); o el 'pastor del ser' que se prepara para 'decir el ser', para ser 'verdad', lugar de acogida del ser (Heidegger); o Sísifo, que piensa la realidad concreta y herida que no puede pensar (Adorno). Se trata siempre de salir de la superestructura, del mundo construido, para volver a la sencillez del ser.

Ahora bien, salida de sí, apertura y experiencia de lo otro, es precisamente lo que ellos consideran como lo propio y esencial de la experiencia estética. En ésta, el espíritu humano entra en contacto con lo que no es él, se 'aliena' hacia lo otro de modo que "se somete a lo que le está polarmente opuesto", la realidad material concreta ${ }^{35}$. Por eso es ámbito de verdad. El acceso al ser, a la vida concreta, a la carne de la realidad, plantea la necesidad del arte y de la poesía como elemento para contrarrestar la tendencia dominadora del concepto, pero sin olvidar su participación. El arte permite el acceso al ser, 
a las cosas mismas; no 'dice' la verdad, sino que la 'tiene', se instala en ella -en el ser- de un salto, inmediatamente. El arte por tanto es experiencia de la cercanía de las cosas, pero le falta la claridad y precisión conceptual; se puede decir que 'piensa' intuitiva y enigmáticamente. Por eso, el arte puede proporcionarle al concepto la 'carne' (la materia) del ser aliviando la tendencia constitutiva del concepto a apropiarse del ser identificándoselo. Es necesario subrayar que la comprensión del arte como experiencia de lo otro, del 'ser', como verdad en suma, no implica suprimir la ilusión estética. La ficción o ilusión artístico/estética es asumida, pero no para contraponerla a la verdad, como hizo Nietzsche, sino -tal como estamos comprobando- para ordenarla precisamente a la propia verdad: "En la ilusión, escribe Adorno, hay una promesa de libertad de ilusión"36. El concepto filosófico permite pensar el ser, tiene claridad y precisión, pero le falta la verdad, la presencia inmediata de las cosas; puede 'decir' la verdad, pero no la 'tiene'. Por eso necesita al arte, pero también el arte lo necesita a él para poder pensar y decir la verdad que posee, y no perderse en el territorio del ser; el concepto le da al arte pensamiento, la 'forma' del ser. El poder del arte por tanto es el que permite contrarrestar la voluntad de identificación del concepto, que tiende a verse a sí mismo en lo otro. La 'alienación' estética, pues, en la que el espíritu sale de sí para reconocerse en lo otro, es la que nos salva de la alienación del mundo tecnificado, en la que el hombre se pierde de sí precisamente porque no sale de sí y sólo se encuentra a sí mismo por todas partes. La excursión al ser requiere del concurso tanto de la filosofía y el concepto, como del arte y su intuitividad. La tensión entre filosofía y poesía permite el nexo razónvida y, por ello mismo, la salvación del hombre de la lógica de dominio de la voluntad de poder. Con esto se cierra el círculo. La toma de conciencia de que en la experiencia estética acontece una apertura a lo otro, empuja a Ortega, Heidegger y Adorno a conectar razón y existencia, filosofía y arte, como verdadero camino de acceso cordial al corazón del ser. Esta es la alternativa que propone la actitud postrágica al programa metafísico tradicional. La convergencia entre lo filosófico-conceptual y lo artístico-poético que la define representa tanto una respuesta al positivismo racionalista y al tragicismo, como un programa existencial de salvación para nuestro mundo gobernado por una voluntad de poder metafísico-técnica exasperante. 


\section{Referencias bibliográficas}

ADORNO, T. W., Ästhetische Theorie, (1969), Gesammelte Schriften, Bd. 7, Frankfurt am Main, Suhrkamp, 1984.

- Der Essay als Form, Noten zur Literatur (1954), GS, Bd. 11.

- Negative Dialektik (1966), GS, Bd. 6.

- Philosophische Terminologie (1962-1963), t. II, Frankfurt a. M., Suhrkamp, 1997.

BAUMGARTEN, A. G., Aesthetica (facsímil de la ed. de Frankfurt, 1750), Hildesheim, G. Olms, 1986.

CEREZO, P., "Poesía y pensamiento en la experiencia de la palabra según M. Heidegger", Cristianismo e ilustración, Madrid, Univ. Pontificia de Comillas, 1990.

- "El claro del mundo: del logos al mito", Nuevo romanticismo: la actualidad del mito, Cuadernos del Seminario Público de la Fundación Juan March, Madrid, nº 1, 1997.

GADAMER, G. H., "W. Dilthey y Ortega y Gasset: un capítulo de la historia intelectual de Europa", Revista de Occidente, 48-49 (1985).

- Los caminos de Heidegger (tr. de A. Ackermann), Barcelona, Herder, 2002.

HEGEL, G. W. F., Vorlesungen über die Philosophie der Weltgeschichte (1822-1828), Bd. 1, Die Vernunft in der Geschichte, her. v. J. Hoffmeister, Hamburg, Felix Meiner Verlag, 1955.

- Grundlinien der Philosophie des Rechts (1821), Werke, Bd. 7, Frankfurt am Main, Suhrkamp, 1986.

HEIDEGGER, M., Brief über den Humanismus (1946), Wegmarken, Gesamtausgabe, Bd. 9, Frankfurt am Main, Klostermann, 1976.

- ... Dichterisch wohnet der Mensch ... (1951), Vorträge und Aufsätze, GA, Bd. 7, 2000.

- Aus der Erfahrung des Denkens (1947), Aus der Erfahrung des Denkens, GA, Bd. 13, 1983.

- Einführung in die Metaphysik (1935), GA, Bd. 40, 1983.

- Einblick in das was ist (1949), GA, Bd. 79, 1994.

- Hölderlin und das Wesen der Dichtung (1936), Erläuterungen zu Hölderlins Dichtung, GA, Bd. 4, 1981.

- Nietzsches Wort 'Got ist tot'(1943), Holzwege, GA, Bd. 5, 1977.

- Nachwort zu 'Was ist Metaphysik'(1943), Wegmarken.

- Spiegel-Gespräch mit M. Heidegger (1966), Reden und andere Zeugnisse eines Lebensweges, GA, Bd. 16, 2000.

- Überwindung der Metaphysik (1936-1946), Vorträge und Aufsätze.

- Wozu Dichter? (1946), Holzwege.

- Was heißt Denken? (1952), Vorträge und Aufsätze.

NIETZSCHE, F., Die Geburt der Tragödie (1872), Sämtliche Werke, Kritische Studienausgabe in 15 Bänden, Bd. 1, her. v. G. Colli und M. Montinari, München, Deutscher Taschenbuch Verlag/De Gruyter, 1980.

- Zur Genealogie der Moral. Eine Streitschrift (1887), KSA, Bd. 5.

- Menschliches, Allzumenschliches (1878), Erster Band, Vorrede 1, KSA, Bd. 2. 
- Nachgelassene Fragmente (1882-1884), KSA, Bd. 10.

- Nachgelassene Fragmente (1887-1889), KSA, Bd. 13.

- Versuch einer Selbstkritik (1886), Die Geburt der Tragödie.

Ortega y Gasset, J., Adán en el paraíso (1910), t. I Obras completas, Madrid, AlianzaRevista de Occidente, 1983.

- Conferencias sobre Goethe (1949), OC, t. IX.

- Meditación de Europa (1949), OC, t. IX.

- Max Scheler (1928), OC, t. IV.

UNAMUNO, M., Del sentimiento trágico de la vida (1912), Madrid, Espasa-Calpe, 1980. 